\title{
Roles of multiple surface sites, long substrate binding clefts, and carbohydrate binding modules in the action of amylolytic enzymes on polysaccharide
}

\section{substrates}

\author{
M. M. NIELSEN ${ }^{1}$, E. S. SEO ${ }^{1}$, A. DILOKPIMOL ${ }^{1}$, J. ANDERSEN ${ }^{1}$, M. ABOU

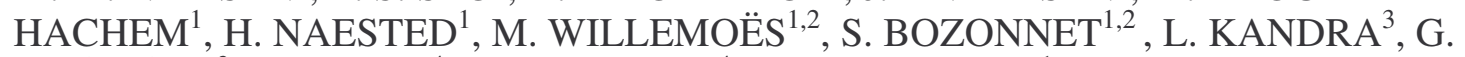 \\ GYÉMÁNT $^{3}$, R. HASER ${ }^{4}$, N. AGHAJARI ${ }^{4}$ \& B. SVENSSON ${ }^{1}$ \\ ${ }^{1}$ Enzyme and Protein Chemistry, BioCentrum-DTU, Technical University of Denmark, Sфltofts Plads, Bldg. \\ 224, DK-2800 Kgs. Lyngby, Denmark, ${ }^{2}$ Carlsberg Laboratory, Valby, Denmark, ${ }^{3}$ Department of \\ Biochemistry, Faculty of Sciences, University of Debrecen, Hungary, ${ }^{4}$ Laboratoire de BioCristallographie, \\ IBCP, CNRS, Lyon, France
}

Germinating barley seeds contain multiple forms of $\alpha$-amylases, which are subject to both differential gene expression and differential degradation as part of the repertoire of starch-degrading enzymes. The $\alpha$-amylases are endo-acting and possess a long substrate binding cleft with a characteristic subsite binding energy profile around the catalytic site. Furthermore, several amylolytic enzymes that facilitate attack on the natural substrate, i.e. the endosperm starch granules, have secondary sugar binding sites either situated on the surface of the protein domain or structural unit that contains the catalytic site or belonging to a separate starch binding domain. The role of surface sites in the function of barley $\alpha$-amylase 1 has been investigated by using mutational analysis in conjunction with carbohydrate binding analyses and crystallography. The ability to bind starch depends on the surface sites and varies for starch granules of different genotypes and botanical origin. The surface sites moreover are candidates for being involved in degradation of polysaccharides by a multiple attack mechanism. Future studies of the molecular nature of the multivalent enzyme-substrate interactions will address surface sites in both barley $\alpha$-amylase 1 and in the related isozyme 2 .

Keywords: multiple $\alpha$-amylase forms; polysaccharide substrates; subsites and secondary binding sites; starch granules; surface plasmon resonance; crystal structures

Correspondence: Birte Svensson, Enzyme and Protein Chemistry, BioCentrum-DTU Technical University of Denmark, Søltofts Plads, Bldg. 224, DK-2800 Kgs. Lyngby, Denmark. Fax: + 45458863 07. E-mail: bis@biocentrum.dtu.dk 


\section{INTRODUCTION}

In Nature starch and related macromolecular substrates are degraded to low molecular weight sugars that provide energy and building blocks for development and growth of living organisms. Amylolytic enzymes catalyse a plethora of reactions. One classical example is during seed germination where hydrolases of complementing specificities cooperate to mobilise storage starch granules as nutrient for the growing plantlet. In germinating barley seeds this enzyme system is controlled by inhibitory proteins and other regulatory proteins.

At the molecular level, interactions between different enzymes and proteins important in starch degradation and reactions between enzymes and substrate polysaccharides are associated with a variety of structural features, of which the mechanism of action is not well understood. One area concerns aspects of the polysaccharide-enzyme interactions, while another relates to the impact on the metabolism of the interaction between regulatory proteins and enzymes and the control of these interactions. Firstly, the enzyme active site cleft that binds amylose and amylopectin - the two polysaccharides of which starch is composed - can be very long comprising 10 or more subsites accommodating consecutive substrate glucosyl residues. Secondly, some amylolytic enzymes interact with carbohydrate at surface binding sites situated on the same protein domain or integral structural unit as the active site or on a separate carbohydrate binding module. Thirdly, certain enzymes are regulated by specific inhibitors some of which are in turn targets of the protein disulfide reductase thioredoxin (Jiao et al., 1993; Maeda et al., 2005).

\section{ISOFORMS AND MULTIPLE FORMS OF $\alpha$-AMYLASE IN GERMINATING BARLEY SEEDS}

During seed germination it has become apparent by applying a proteomics approach consisting of western blotting of 2D electrophoretic gels and mass spectrometry that different isoforms and multiple forms are found of two $\alpha$-amylase (E.C. 3.2.1.1) isozyme families, AMY1 and AMY2 (Bak-Jensen et al., 2007). These enzymes hydrolyse $\alpha-1,4$ 
glucosidic bonds in amylose and amylopectin in an endo-fashion, while the exo-acting $\beta$ amylase (E.C. 3.2.1.2) releases maltose from non-reducing ends, and two minor activities, $\alpha$-glucosidase (E.C. 3.2.1.20) and $\alpha$-1,6 debranching limit dextrinase (E.C. 3.2.1.142) contribute to convert starch to fermentable sugars. The two barley $\alpha$-amylase isozymes, AMY1 and AMY2, share approximately 80\% sequence identity, but possess different properties (Bush et al., 1989; Jensen et al., 2003). A total of four and six genes encode family AMY1 and AMY2 members, respectively. Within a family the sequence identity is $95 \%$ or higher, but nothing is known on functional variation between members of the same family. The 10 genes are differentially expressed in the seed during germination to produce one AMY1 and two AMY2 members (Figure 1 A, B). Proteome analysis confirmed that AMY1 is a minor isozyme and demonstrated that one of the two AMY2 members is preferentially degraded during the course of the germination (BakJensen et al., 2007).

Current structure/function relationship investigations of barley $\alpha$-amylase focus on multivalent reactions with polysaccharides. In addition, efficient heterologous expression systems have been established for the minor enzymes $\alpha$-glucosidase (Naested et al., 2006) and limit dextrinase (Vester-Christensen et al., unpublished) using high cell density fermentation enabling future mutational analysis of their structure/function relationships. Finally, a single mutant, A42P AMY2, which behaves as AMY2 with regard to enzyme activity, stability, interaction with BASI, and dependence on calcium ions, was obtained by degenerate oligonucleotide gene shuffling and screening (Fukuda et al., 2005) and is currently applied for the first mutational analysis in AMY2, the major isozyme in the germinating seed.

Specific proteinaceous inhibitors in the seed interact with certain amylolytic enzymes in particular the double-headed barley $\alpha$-amylase/subtilisin inhibitor (BASI), a member of the Kunitz soybean trypsin inhibitor family which acts on AMY2 and subtilisin-type proteases (Nielsen et al., 2003; Svensson et al., 2004; Bønsager et al., 2005), and the limit dextrinase inhibitor that belongs to the CM-proteins (MacGregor, 2004). Furthermore, selected enzymes and inhibitors are targets of the disulfide reductase thioredoxin h (Jiao et al., 1993; Maeda et al., 2005). It remains to be proven, however, if disulfide bond reduction in these cases influences on the activity. Recently, 
we solved the first structure of complex between thioredoxin $\mathrm{h}$ and a target protein, the barley $\alpha$-amylase/subtilisin inhibitor (Maeda et al., 2006). Clearly thioredoxin $h$ recognises BASI and structural motifs from the thioredoxin $\mathrm{h}$ are crucial for the complex formation. Thus on the basis of a variety of classical biochemical analyses one can define a network of protein-protein interactions in a system related to breakdown of starch.

\section{MODULAR ARCHITECTURE IN GLYCOSIDE HYDROLASE CLAN H}

Barley AMY1 and AMY2 belong to the large glycoside hydrolase family 13 (GH13) that comprises enzymes of a wide variety of specificities (Stam et al., 2006) and forms glycoside hydrolase clan H together with GH70 and GH77 (http://www.cazy.org). All GH-H members contain a prototype $(\beta / \alpha)_{8}$-barrel domain A carrying the catalytic groups. Mostly, a small domain B protrudes between the third $\beta$-strand and helix of the $(\beta / \alpha)_{8^{-}}$ barrel, which together with $\beta \rightarrow \alpha$ loops from domain A forms the substrate binding cleft and the catalytic site. Certain GH-H members contain additional domains before and after the catalytic domain (MacGregor et al., 2001), the most impressive case being GH70 that has a circularly permutated catalytic $(\beta / \alpha)_{8}$-barrel domain (MacGregor et al., 1996), and for which the first solved three-dimensional structure (Vujičić-Žagar et al., 2007) revealed additional domains in some cases formed by interacting sequence repeats located in the sequence before and after the catalytic domain. The spatial changes in the domain architecture represent just one of the future challenges in improving the structural basis for understanding the mechanism of the different reactions catalysed by GH70.

Most $\alpha$-amylases have a $\mathrm{C}$-terminal anti-parallel $\beta$-sheet domain $\mathrm{C}$ for which so far the function remains to be identified. However, the distinct binding of oligosaccharides to this domain at the so-called "sugar tongs" site found in the crystal structure of AMY1 (Robert et al., 2003, 2005), suggests a function for domain C in at least some plant $\alpha$-amylases. This binding was so far not seen in the structure of AMY2 (Kadziola et al., 1998) emphasising yet another difference between AMY1 and AMY2. Finally, a few $\alpha$-amylases carry extra C-terminal domains that are involved in starch binding (Janecek et al., 2003; Rodriguez-Sanoja et al., 2005; Machovic and Janecek, 2006a, 2006b). This particular property and the modular organisation confer potential for 
engineering properties of $\mathrm{GH}-\mathrm{H}$ enzymes by manipulation of the multidomain architecture.

\section{THE LONG SUBSTRATE BINDING CLEFT}

AMY1 and AMY2 contain long substrate binding sites similarly to liquefying bacterial $\alpha$-amylases (Dauter et al., 1999; Brzozowski et al., 2000). Mutating AMY1 at individual subsites along the cleft affected the relative specificity for insoluble, longer soluble, and oligosaccharide substrates differently. Such mutations thus clearly modified action patterns as shown by product profile analysis using oligosaccharide substrates (Matsui and Svensson, 1997; Gottschalk et al., 2001; Mori et al., 2001, 2002; Bak-Jensen et al., 2004). For example, the subsite -6 mutant Y105A had $140 \%$ of the activity of AMY1 wild-type against insoluble Blue Starch, but retained $<1 \%$ activity for oligosaccharides. Thus the aromatic group at subsite -6 in the wild-type enzyme did not at all contribute to efficient interaction for starch degradation, but seemed in contrast strictly required for action on oligosaccharides (Bak-Jensen et al., 2004). By analysing subsite maps of mutants at the outer subsites -6 and +4 in AMY1 using a novel series of aglycon-labelled maltooligosaccharides of DP up to 12 (Kandra et al., 2001, 2002; Gyémánt et al., 2002), new insight was achieved on the dynamics and plasticity of the binding site affinity profile. This includes variation of binding energies at individual subsites in response to distantly situated mutations, i.e. communication occurs in the enzyme-substrate complex along the cleft formed by domains A and B (Kandra et al., 2006). One remarkable feature indicated by this subsite mapping was the outer barriers (repulsive energy) at subsites -8 and $+3 /+4$ of $0.2-2 \mathrm{~kJ} / \mathrm{mol}$ that defined the length of the binding site. Barriers in addition occurred internally in the cleft and both these barriers of $0.3-3.0$ $\mathrm{kJ} / \mathrm{mol}$ at subsite -3 and -5 as well as the outer barriers were sensitive to the mutations at outer subsites, which converted some of the barriers to binding subsites (Figure 2). Thus the subsite energy profile - and as a consequence the composition of oligosaccharide product mixtures - was amenable to manipulation as shown here for AMY1 by removal and introduction of aromatic side-chains at the outer subsites -6 (Y105A) and +4 (T212Y). This illustrates the potential available for designing oligosaccharide product compositions. Remarkably, the wild-type AMY1 $\mathrm{Tyr}^{105}$ at subsite -6 superimposed 
excellently with aromatic side chains in structures of liquefying bacterial $\alpha$-amylases (Kandra et al., 2006).

\section{ENZYME SURFACE SITES IN INTERACTION WITH POLYSACCHARIDES}

The interplay between amylolytic enzymes and polysaccharides occurs also beyond the substrate binding cleft, i.e. at binding sites situated elsewhere on the enzyme surface. The presence of one or more binding sites outside of the active site region leads to multivalent substrate interaction and there is a need for disclosing how such secondary sites may co-operate with the active site to degrade different types of polysaccharide substrates. In those cases where an enzyme has more than one surface site a fairly complicated scheme of multivalent interactions is envisaged. An early example of a starch-active, multidomain enzyme that exerts multivalent substrate interaction is the GH13 member cyclodextrin glucosyltransferase (CGTase) from Bacillus circulans that has a C-terminal starch binding domain (SBD) seen in the crystal structure (Penninga et al., 1996; Strokopytov et al., 1996). Other amylolytic enzymes are also described to possess carbohydrate binding sites outside of the active site region (Gibson and Svensson, 1987; Larson et al., 1994; Kadziola et al., 1998; Dauter et al., 1999; Brzozowski et al., 2000; Skov et al. 2002; Robert et al., 2003). These sites together with an anticipated multiplicity of modes for accommodation of polysaccharide substrate chains in the active cleft (Bak-Jensen et al., 2004) merit analysis with focus on polysaccharide binding and catalysis. In fact the first GH13 surface site was reported in AMY2 of barley as identified by differential chemical modification of tryptophanyl residues protected by $\beta$ cyclodextrin ( $\beta$-CD) (Gibson and Svensson, 1987). Subsequently both mutagenesis (Søgaard et al., 1993) and crystallography (Kadziola et al., 1998) confirmed the presence and carbohydrate binding ability of this site containing $\operatorname{Trp}^{276}$ and $\operatorname{Trp}^{277}$ (corresponding to $\operatorname{Trp}^{278}$ and $\operatorname{Trp}^{279}$ in AMY1). The adjacent tryptophans are seen to stack onto neighbouring glucosyl units in oligosaccharides in structures of complexes obtained for both AMY1 (Robert et al., 2003, 2005) and AMY2 (Kadziola et al., 1998). The W279A AMY1 mutant showed 3- and 10-fold decrease in affinity for $\beta-C D$ and starch granules, respectively (Søgaard et al., 1993), but an extremely low yield of this mutant - at that 
time produced in Saccharomyces cerevisiae - excluded further biochemical and structural analysis of the carbohydrate binding.

A second surface site named "a pair of sugar tongs" was discovered in the crystal structure of AMY1 in complex with the non-hydrolysable methyl 4',4",4",'-trithio maltotetraoside and subsequently shown also for the inactive catalytic nucleophile mutant D180A in complex with maltoheptaose (Robert et al., 2003, 2005) (Figure 3). $\mathrm{Tyr}^{380}{ }_{\text {AMY }}$ in this site moves and captures the oligosaccharide (Figure 3), but AMY2 crystal structures did not bind carbohydrate at the equivalent site (Kadziola et al., 1998), although $\mathrm{Tyr}^{378}{ }_{\mathrm{AMY} 2}$ (corresponding to $\mathrm{Tyr}^{380}{ }_{\mathrm{AMY} 1}$ ) was conserved. Several AMY1 "sugar tongs" mutants were prepared and characterized with respect to enzymatic activity for different substrates, binding of $\beta-\mathrm{CD}$, adsorption to starch granules, and degree of multiple attack (Bozonnet et al., 2007; Nielsen et al., in preparation).

A procedure was developed to measure $\beta-\mathrm{CD}$ binding by using surface plasmon resonance ("Biacore"), where the enzyme was biotinylated and attached to a strepavidincoated chip. This allowed confirming the involvement of $\mathrm{Tyr}^{380}$ in oligosaccharide binding, consistent with $\mathrm{Tyr}^{380}$ in the crystal structure participating in numerous interactions with glucopyranosyl moieties of the ligand (Robert et al., 2003). Moreover, the properties of an AMY2 mimic S378P AMY1 were found to be similar to those of wild-type AMY1 (Bozonnet et al., 2007). The Pro ${ }^{376}$ characteristic of the AMY2 sequence, as deduced from the introduction into AMY1 of S378P, did not result in lower affinity for oligosaccharide or lack of binding in the crystal structure (Bozonnet et al., 2007). Support therefore remains to be obtained for a proposed loss of flexibility due to Pro $^{376}$ of the AMY2 loop carrying Tyr $^{378}$ to be the reason for lack of oligosaccharide binding at the "sugar tongs" in the AMY2 structure. Consistent results were obtained when analysing binding of the various "sugar tongs" mutants to barley starch granules. The Y380A mutant had reduced affinity by about 13-fold and the catalytic efficiency to about $10 \%$ of wild-type AMY1 against starch granules. Several "sugar tongs" mutants have been crystallised (Tranier et al., 2005) and two structures were solved recently, which confirmed both the loss of oligosaccharide binding when $\mathrm{Tyr}^{380}$ was replaced by an aliphatic residue and the ability of S378P to accommodate sugar ligand at "the sugar tongs" (Bozonnet et al., 2007). Currently, a series of mutants of $\operatorname{Trp}^{278} \operatorname{Trp}^{279}$ on the 
surface of the catalytic $(\beta / \alpha)_{8}$-barrel domain of AMY1 are being studied to disclose if specific functional roles exist for this and the "sugar tongs" sites, respectively, in interaction with starch granules, poly- and oligosaccharide substrates.

The affinity of AMY1 for starch granules was found in preliminary experiments to depend on the botanical source and the genotype. AMY1 showed the highest affinity for the waxy-type and the lowest affinity for high amylose maize starch granules. The $K_{\mathrm{d}}$ values of AMY1 wild-type binding were determined by an adsorption procedure as described (Bozonnet et al., 2007) and found in the range of 0.16-0.46 mg/ml, comparable with the $K_{\mathrm{d}}$ for AMY1 binding to normal barley starch granules (Bozonnet et al., 2007). The affinities will be further analysed for surface site mutants (Nielsen et al., in preparation).

\section{STARCH BINDING DOMAINS}

Carbohydrate binding sites are also found on carbohydrate binding modules (CBMs). In the case of starch degradation, the first starch binding domain (SBD) was very early identified in fungal glucoamylases (Svensson et al., 1982; Janecek et al., 2003) and has later been classified as CBM20 (http://www.cazy.org/). An example of multivalent substrate interaction is found in cyclodextrin glucosyltransferase (CGTase) from Bacillus circulans that has a C-terminal CBM20 SBD containing two binding sites, proposed from examination of the crystal structure to act as an enzyme attachment point and to guide the substrate chain into the active site, respectively (Strokopytov et al., 1996). A potential substrate selectivity of such sites, which is not very well explored, may reflect different functional roles as well as the substrate repertoire in the habitat where the enzyme prevails. A few $\alpha$-amylases possess an SBD of CBM20 connected to the C-terminus of domain C via a short linker or alternatively via a domain D as in CGTase (Janecek et al., 2003). Fusion of SBD from Aspergillus niger glucoamylase to AMY1, including a long linker, to yield AMY1-SBD enhanced activity towards barley starch granules by a factor of 15 (Juge et al., 2006). Similar fusions of a bacterial $\alpha$-amylase and SBD from a CGTase also showed increased activity on starch (Ohdan et al., 2000).

Recently, more CBM families are described as starch binding domains, thus currently including CBM20, 21, 25, 26, 34, 41, 45, and 48 (http://www.cazy.org/). Only 
a few members of the newly described SBD-types, however, have been demonstrated to interact with starch. A noticeable example is CBM41 in surface-anchored pullulanases from Streptococcus pneumoniae and Streptococcus pyogenes that interacts with intracellular lung glycogen and thus may be a novel target in the combat of pathogenic streptococci (van Bueren et al., 2007). Three-dimensional structures are available for all SBDs except CBM45 and CBM48. The diversity of the SBDs represents a rich source for future protein engineering. Some current studies focus on characterising domains from the newer of the starch binding CBM families.

SBDs of CBM20 are by far the best characterised with respect to structure and function (Sorimachi et al., 1996; Giardina et al., 2001; Morris et al., 2005). The AMY1SBD fusion also increased the degree of multiple attack (DMA) towards amylose DP440 to 3.0 from 1.9 of the wild-type enzyme (Kramhøft et al., 2005; Juge et al., 2006). The SBD provides two binding sites (Giardina et al., 2001) in addition to those found in AMY1 itself. The same A. niger glucoamylase SBD was able to act as an independent protein module and to form supramolecular structures with amylose chains (Giardina et al., 2001; Morris et al., 2005). CBM20 domains are also found in mammals (in laforin, genethonin-1, AMP-activated protein kinase; Machovic and Janecek, 2006a, 2006b) as well as in higher plants (in glucan water dikinase 3; Baunsgaard et al., 2005). Production of these domains in recombinant form and characterization of the binding properties are in progress (Christiansen et al., unpublished).

\section{DEGREE OF MULTIPLE ATTACK}

Polysaccharides by some enzymes are depolymerised in a multiple attack mechanism in which more than one substrate bond is hydrolysed in a single enzyme-substrate encounter. Several $\alpha$-amylases use multiple attack (Robyt and French, 1967) and a similar mode of action is referred to as processivity for other polysaccharide degrading enzymes, e.g. cellulases, pectinases and chitinases (Breyer and Matthews, 2001). It is not clearly understood how interactions and conformational changes in enzyme and substrate drive these attacks and how secondary binding sites on the enzyme surface can play a role in the mechanism. 
Barley $\alpha$-amylases cleave on average two bonds in amylose after the initial endohydrolysis (Kramhøft et al., 2005). The DMA varied for AMY1 mutants from 0.9 for M53E at subsite -2 to 3.3 for $\mathrm{Y} 105 \mathrm{~A}$ at subsite -6 (Kramhøft et al., 2005). The distribution of oligosaccharide products determined by HPLC suggested that although DMA was affected by the locally modified structure of binding subsites, one or more sites outside the long substrate binding cleft seemed to be involved as well. An example is the AMY1-SBD fusion that produced slightly longer oligosaccharides compared to both other mutants and wild-type AMY1 and increased DMA to 3.0 (Kramhøft et al., 2005; Juge et al., 2006). It cannot be excluded that the two sugar binding sites on the surface of the SBD provide an extension of the surface binding site(s) on AMY1 to favour multiple attack, thus providing more support for distal binding sites being involved in DMA. This agreed with DMA of the "sugars tongs" mutant Y380A AMY1 being reduced to 0.9 (Bozonnet et al., 2007). Evaluation of DMA of more surface site mutants and determination of the corresponding product profiles is in progress. So far the hypothesized participation of surface sites in multiple attack on amylose has been confirmed for more "sugar tongs" mutants (Seo et al., unpublished). Furthermore, the "sugar tongs" loss in DMA predominated over the increase in DMA for the subsite -6 Y105A single mutant to 3.3 (Kramhøft et al., 2005; Juge et al., 2006) in two dual site mutants which showed comparable loss in DMA as the single "sugar tongs" mutant (Seo et al., unpublished).

\section{SUMMARISING ENZYME AND POLYSACCHARIDE INTERACTIONS: BINDING, SPECIFICITY, AND MECHANISM OF ACTION}

In addition to the above analyses of the role of the long substrate binding cleft, the binding sites on the enzyme surface, and starch binding domains in the action on starch granules and the polysaccharide amylose DP440, also hydrolysis of the branched amylopectin that is the major component of normal starch has special interest. Amylopectin is used for a range of important applications in the food industry and in biotechnology. In this molecule $\alpha-1,4$ glucosidic bonds occur in shorter stretches of $\alpha$ glucan chain that carry branches formed by $\alpha-1,6$ substitution of main chain residues to give an intricate structural cluster organisation of the very large polysaccharide molecule. 
The hydrolysis of amylopectin catalysed by AMY1 proceeds according to a biexponential kinetics model containing a fast and a slow component (Willemoës et al., unpublished). The structural basis for this kinetics is not resolved. It is proposed, however, that the fast rate of hydrolysis corresponds to hydrolysis in branches (referred to as A-chains), whereas the more interior B-chains that carry A-chains are hydrolysed at a slower rate. Noticeably, $\beta-\mathrm{CD}$ affected only the fast rate component of the kinetics and because $\beta-C D$ has stronger binding to the "sugar tongs", this site is proposed to play a special role in interaction with amylopectin. This point is further addressed by studies on the interaction between different starch genotypes and "sugar tongs" mutants (Nielsen et al., in preparation).

\section{CONCLUSION AND PROSPECTS}

Certain features of the mechanism and the structural basis for characteristic properties of $\alpha$-amylases are still not well understood, although several $\alpha$-amylases have been subjected to thorough structure/function relationship investigations. AMY1 and AMY2 in this context display important differences despite their homology, making them an obvious choice for disclosing structural features responsible for specific properties. There is an increasing amount of evidence for a functional role of the "sugar tongs" site as well as the first identified surface site on the domain A in AMY1 in discrimination between amylopectin and amylose, starch granules and other sugars, and for contributing to the multiple attack. The various multivalent substrate interactions characteristic of amylolytic and related enzymes represent a common feature for proteins and macromolecular carbohydrates interactions in which fairly subtle protein structural changes moreover can have a major impact. A better understanding of the multivalent interactions will provide a basis for development of amylolytic enzymes for hydrolysis of native starch granules which has an application potential for example in production of bio ethanol (Robertson et al. 2006).

\section{Acknowledgements}

We are grateful to Camilla Christiansen for useful discussions and to Andreas Blennow for collaboration on starch granule adsorption. This work was supported by the EU- 
project GECLYC (QLK3-CT-2001-00149), the Danish Natural Science Research Council, the Danish Research Council for Technology and Production, the Carlsberg Foundation, the Centre for Advanced Food Studies, a postdoctoral fellowship from the Korean Research Foundation (to ESS), the H.C. Ørsted postdoc program at DTU (to ESS), and a Ph.D. fellowship from DTU (to MMN).

\section{REFERENCES}

Bak-Jensen, K.S., André, G., Gottschalk, T.E., Paës G., Tran, V., and Svensson, B. (2004) Tyrosine 105 and threonine 212 at outermost substrate binding subsites 6 and +4 control substrate specificity, oligosaccharide cleavage patterns, and multiple binding modes of barley $\alpha$-amylase 1. J. Biol. Chem. 279, 1009310102.

Bak-Jensen K.S., Laugesen, S., Østergaard, O., Finnie, C., Roepstorff, P., and Svensson, B. (2007) Spatio-temporal profiling and degradation of $\alpha$-amylase isozymes during barley seed germination. FEBS J. 274, 2552-2565.

Baunsgaard, L., Lütken, T., Mikkelsen, R., Glaring, M.A., Pham, T.T., and Blennow, A. (2005) A novel isoform of glucan water dikinase phosphorylates prephosphorylated $\alpha$-glucans and is involved in starch degradation in Arabidopsis. Plant J. 41, 595-605.

Bønsager, B.C., Nielsen, P.K., Abou Hachem, M., Prætorius-Ibba, M., and Svensson, B. (2005) Mutational analysis of the $\beta$-trefoil fold protein barley $\alpha$ amylase/subtilisin inhibitor probes hot spots for the interaction with barley $\alpha$ amylase. J. Biol. Chem. 280, 14855-14864.

Bozonnet, S., Jensen, M.T., Nielsen, M.M., Aghajari, N., Kramhøft, B., Willemoës, M., Hansen, M.N., Tranier, S., Haser, R., and Svensson B. (2007) The "pair of sugar tongs" site on the non-catalytic domain $\mathrm{C}$ of barley $\alpha$-amylase participates in substrate binding and activity. Submitted.

Breyer, W.A., and Matthews, B.W. (2001) A structural basis for processivity. Protein Sci. 10, 1699-1711. 
Brzozowski, A.M., Lawson, D.M., Turkenberg, J.P., Bisgård-Frantzen, H., Svendsen, A., Borchert, T.V., Dauter, Z., Wilson, K.S., and Davies, G. (2000) Structural analysis of a chimeric bacterial $\alpha$-amylase. High-resolution analysis of native and ligand complexes. Biochemistry 39, 9099-9107.

Bush, D.A., Sticher, L., Van Huystee, R.B., Wagner, D., and Jones, R.L. (1989) The calcium requirement for stability and enzymatic activity of two isoforms of barley $\alpha$-amylase. J. Biol. Chem. 264, 19392-19398.

Dauter, Z., Dauter, M., Brzozowski, A.M., Christensen, S., Borchert, T.V., Beier, L., Wilson, K.S., and Davies, G.J. (1999) X-ray structure of Novamyl, the fivedomain "maltogenic" $\alpha$-amylase from Bacillus stearothermophilus: maltose and acarbose complexes at 1.7 A resolution. Biochemistry 38, 8385-8392.

Fukuda K., Jensen, M.H., Haser, R., Aghajari, N., and Svensson, B. (2005) Biased mutagenesis in the $\mathrm{N}$-terminal region by degenerate oligonucleotide gene shuffling enhances secretory expression of barley $\alpha$-amylase 2 in yeast. Protein Eng. Des. Sel. 18, 515-526.

Giardina, T., Gunning, A.P., Juge, N., Faulds, C.B., Furniss, C.S.M., Svensson, B., Morris, V.J., and Williamson, G. (2001) Both binding sites of the starch-binding domain of Aspergillus niger glucoamylase are essential for inducing a conformational change in amylose. J. Mol. Biol. 313, 1149-1159.

Gibson, R.M., and Svensson, B. (1987) Identification of tryptophanyl residues involved in binding of carbohydrate ligands to barley $\alpha$-amylase 2. Carlsberg Res. Commun. 52, 373-379.

Gottschalk, T.E., Tull, D., Aghajari, N., Haser, R., and Svensson, B. (2001) Specificity modulation of barley $\alpha$-amylase through biased random mutagenesis involving a conserved tripeptide in $\beta \rightarrow \alpha$ loop 7 of the catalytic $(\beta / \alpha)_{8}$-barrel domain. Biochemistry 40, 12844-12854.

Gyémánt, G., Hovánszki, G., and Kandra, L. (2002) Subsite mapping of the binding region of $\alpha$-amylases with a computer program. Eur. J. Biochem. 269, 5157-5162. 
Janecek, S., Svensson, B., and MacGregor, E.A. (2003) Relation between domain evolution, specificity, and taxonomy of the $\alpha$-amylase family members containing a C-terminal starch-binding domain. Eur. J. Biochem. 270, 635-645.

Jensen, M.T., Gottschalk, T.E., and Svensson, B. (2003) Differences in conformational stability of barley $\alpha$-amylase isozymes 1 and 2 . Role of charged groups and isozyme 2 specific salt-bridges. J. Cereal Sci. 38, 289-300.

Jiao, J.-A., Yee, B.C., Wong, J.H., Kobrehel, K., and Buchanan, B.B. (1993) Thioredoxin-linked changes in regulatory properties of barley $\alpha$ amylase/subtilisin inhibitor protein. Plant Physiol. Biochem. 31, 799-804.

Juge, N., Nøhr, J., Le Gal-Coëffet, M.-F., Furniss, C.S.M., Kramhøft, B., Planchot, V., Archer, D.B., Williamson, G., and Svensson, B. (2006) The activity of barley $\alpha$ amylase on starch granules is enhanced by fusion of a starch binding domain from Aspergillus niger glucoamylase. Biochim. Biophys. Acta 1764, 275-284.

Kadziola, A., Søgaard, M., Svensson, B., and Haser, R. (1998) Molecular structure of a barley $\alpha$-amylase-inhibitor complex: implications for starch binding and catalysis. J. Mol. Biol. 278, 205-217.

Kandra, L., Gyémánt, G., Pál, M., Petró, M., Remenyik, J., and Lipták, A. (2001) Chemoenzymatic synthesis of 2-chloro-4-nitrophenyl $\beta$-maltoheptaoside acceptor-products using glycogen phosphorylase b. Carbohydr. Res. 333, 129136.

Kandra, L., Gyémánt, G., Remenyik, J., Hovanszki, G., and Liptak, A. (2002) Action pattern and subsite mapping of Bacillus licheniformis $\alpha$-amylase (BLA) with modified maltooligosaccharide substrates. FEBS Lett. 518, 79-82.

Kandra, L., Abou Hachem, M., Gyémánt, G., Kramhøft, B., and Svensson, B. (2006) Mapping of barley $\alpha$-amylases and outer subsite mutants reveals dynamic highaffinity subsites and barriers in the long substrate binding cleft. FEBS Lett. 580, 549-563.

Kramhøft, B., Bak-Jensen, K.S., Mori, H., Juge, N., Nøhr J., and Svensson B. (2005) Multiple attack, kinetic parameters, and product profiles in amylose hydrolysis by barley $\alpha$-amylase 1 variants. Biochemistry 44, 1824-1832. 
Larson, S.B., Greenwood, A., Cascio, D., Day, J., and McPherson, A. (1994) Refined molecular structure of pig pancreatic $\alpha$-amylase at 2.1 A resolution. J. Mol. Biol. 235, 1560-1584.

MacGregor, E.A. (2004) The proteinaceous inhibitor of limit dextrinase in barley and malt. Biochim. Biophys. Acta 1696, 165-170.

MacGregor, E.A., Janecek, S., and Svensson, B. (2001) Relationship of sequence and structure to specificity in the $\alpha$-amylase family of enzymes. Biochim. Biophys. Acta 1546, 1-20.

MacGregor, E.A., Jespersen, H.M., and Svensson, B. (1996) A circularly permuted $\alpha-$ amylase-type $\alpha / \beta$-barrel in glucan-synthesizing glucosyltransferases. FEBS Lett. 378, 263-266.

Machovic, M., and Janecek, S. (2006a) The evolution of putative starch-binding domains. FEBS. Lett. 580, 6349-6456.

Machovic, M., and Janecek, S. (2006b) Starch-binding domains in the post-genome era. Cell. Mol. Life Sci. 63, 2710-2724.

Maeda, K., Finnie, C., and Svensson, B. (2005) Identification of thioredoxin h-reducible disulphides in proteomes by differential labeling of cysteines: Insight into recognition of proteins in barley seeds by thioredoxin h. Proteomics 5, 16341644.

Maeda, K., Hägglund, P., Finnie, C., Svensson, B., and Henriksen, A. (2006) Structural basis for target protein recognition by the protein disulfide reductase thioredoxin Structure 14, 1701-1710.

Matsui, I., and Svensson, B. (1997) Improved activity and modulated action pattern obtained by random mutagenesis at the fourth $\beta-\alpha$ loop involved in substrate binding to the catalytic $(\beta / \alpha)_{8}$-barrel domain of barley $\alpha$-amylase $1 . \mathrm{J}$. Biol. Chem. 272, 22456-22463.

Mori, H., Bak-Jensen, K.S., Gottschalk, T.E., Motawia, M.S., Damager, I., Møller, B.L., and Svensson, B. (2001) Modulation of activity and substrate binding modes by single and double subsites $+1 /+2$ and $-5 /-6$ mutation of barley $\alpha$-amylase 1 . Eur. $J$. Biochem. 268, 6545-6558. 
Mori, H., Bak-Jensen, K.S., and Svensson, B. (2002) Barley $\alpha$-amylase Met53 situated at the high-affinity subsite -2 belongs to a substrate binding motif in the $\beta \rightarrow \alpha$ loop 2 of the catalytic $(\beta / \alpha)_{8}$-barrel and is critical for activity and substrate specificity Eur. J. Biochem. 269, 5377-5390.

Morris, V.J., Gunning, A.P., Faulds, C.B., Williamson, G., and Svensson, B. (2005) AFM images of complexes between amylose and Aspergillus niger glucoamylase mutants, native and mutant starch binding domains: a model for the action of glucoamylase. Starch 57, 1-7.

Naested, H., Kramhøft, B., Lok, F., Bojsen, K., Yu, S., and Svensson, B. (2006) Production of enzymatically active recombinant full-length barley high pI $\alpha$ glucosidase of glycoside hydrolase family 31 by high cell-density fermentation of Pichia pastoris and affinity purification. Protein Express. Purif. 46, 56-63.

Nielsen, P.K., Bønsager, B.C., Berland, C.R., Sigurskjold, B.W., and Svensson, B. (2003) Kinetics and energetics of the binding between barley $\alpha$-amylase/subtilisin inhibitor and barley $\alpha$-amylase 2 analyzed by surface plasmon resonance and isothermal titration calorimetry. Biochemistry 42, 1478-1487.

Ohdan, K., Kuriki, T., Takata, H., Kaneko, H., and Okada, S. (2000) Introduction of raw starch-binding domains into Bacillus subtilis $\alpha$-amylase by fusion with the starch-binding domain of Bacillus cyclomaltodextrin glucanotransferase. Appl. Environ. Microbiol. 66, 3058-3064.

Penninga, D., van der Veen, B.A., Knegtel, R.M., van Hijum, S.A., Rozeboom, H.J., Kalk, K.H., Dijkstra, B.W., and Dijkhuizen, L. (1996) The raw starch binding domain of cyclodextrin glycosyltransferase from Bacillus circulans strain 251. J. Biol. Chem. 271, 32777-32784.

Robert, X., Haser, R., Gottschalk, T.E., Ratajczak, F., Driguez, H., Svensson, B., and Aghajari, N. (2003) The structure of barley $\alpha$-amylase 1 reveals a novel role of domain C in substrate recognition and binding: "A pair of sugar tongs". Structure 11, 973-984.

Robert, X., Haser, R., Mori, H., Svensson, B., and Aghajari, N. (2005) Oligosaccharide binding to barley $\alpha$-amylase 1. J. Biol. Chem. 280, 32968-32978. 
Robertson, G.H., Wong, D.W.S., Lee, C.C., Wagschal, K., Smith, M.R., and Orts, W.J., (2006) Native or raw starch digestion: A key step in energy efficient biorefining of grain J. Agri. Food Chem. 54, 353-365.

Robyt, J.F., and French, D. (1967) Multiple attack hypothesis of $\alpha$-amylase action: action of porcine pancreatic, human salivary, and Aspergillus oryzae $\alpha$-amylase. Arch. Biochem. Biophys. 122, 8-16.

Rodrigues-Sanoja, R., Ruiz, B., Guyot, J.P., and Sanchez, S. (2005) Starch-binding domain affects catalysis in two Lactobacillii. Appl. Environ. Microbiol. 71, $297-$ 302.

Skov, L.K., Mirza, O., Sprogøe, D., Dar, I., Remaud-Simeon, M., Albenne, C., Monsan, P., and Gajhede, M. (2002) Oligosaccharide and sucrose complexes of amylosucrase. Structural implications for the polymerase activity. J. Biol. Chem. 277, 47741-47747.

Søgaard, M., Kadziola, A., Haser R., and Svensson B. (1993) Site-directed mutagenesis of histidine 93, aspartic acid 180, glutamic acid 205, histidine 290, and aspartic acid 291 at the active site and tryptophan 279 at the raw starch binding site in barley $\alpha$-amylase 1. J. Biol. Chem. 268, 22480-22484.

Sorimachi, K., Le Gal-Coëffet, M.-F., Willamson, G., Archer, D.B., and Williamson, M.P. (1997) Solution structure of the granular starch binding domain of glucoamylase from Aspergillus niger bound to $\beta$-cyclodextrin. Structure 5, 647661.

Stam, M.R., Danchin, E.G.J., Rancurel, C., Coutinho, P.M., and Henrissat, B. (2006) Dividing the large glycoside hydrolase family 13 into subfamilies: towards improved functional annotations of $\alpha$-amylase-related proteins. Protein Eng. Des. Sel. 19, 555-562.

Strokopytov, B., Knegtel, R.M., Penninga, D., Rozeboom, H.J., Kalk, K.H., Dijkhuizen, L., and Dijkstra, B.W. (1996) Structure of cyclodextrin glycosyltransferase complexed with a maltononaose inhibitor at 2.6 angstrom resolution. Implications for product specificity. Biochemistry 35, 4241-4249. 
Svensson, B., Fukuda, K., Nielsen, P.K., and Bønsager, B.C. (2004) Proteinaceous $\alpha$ amylase inhibitors. Biochim. Biophys Acta 1696, 145-156.

Svensson, B., Pedersen, T.G., Svendsen, I., Sakai, T., and Ottesen, M. (1982) Characterization of two forms of glucoamylase from Aspergillus niger. Carlsberg Res. Commun. 47, 55-69.

Tranier, S., Deville, K., Robert, X., Bozonnet, S., Haser, R., Svensson, B., and Aghajari, N. (2005) Insights into the "pair of sugar tongs" surface binding site in barley $\alpha$-amylase isozymes and crystallization of appropriate sugar tongs mutants. Biologia 60/Suppl. 16, 37-46.

van Bueren, A.L., Higgins, M., Wang, D., Burke, R.D., and Boraston, A.B. (2007) Identification and structural basis of binding to host lung glycogen by streptococcal virulence factors. Nat. Struc. Mol. Biol. 14,76-84.

Vujičić-Žagar, A., Pijning, T., Kralj, S., Eeuwerna, W., Dijkhuizen, L., and Dijkstra, B.W. (2007) Structural and functional characterization of Lactobacillus reuteri glucansucrase $\Delta \mathrm{N}-\mathrm{GTF} 180$, a GH family 70 enzyme. In: Buchholz, K., Jördening, H.J., Seibel, J., and Holtman, D. editors. Book of Abstracts - $7^{\text {th }}$ Carbohydrate Bioengineering Meeting, Braunschweig, Dechema, p. 35. 


\section{LEGENDS TO FIGURES}

Figure 1. Appearance of barley $\alpha$-amylase during days 3-6 of germination in the presence and in the absence of externally added gibberellic acid (GA). A. Western blots of $2 \mathrm{D}$ gel electrophoretic gels of seed extracts using antibodies raised against AMY2. B. Distribution of enzyme isoforms in trains of full-length spots as well as of degraded forms identified using mass spectrometry. Spot \#1 is AMY1, \#2-7 contain full length AMY2, and other numbered spots contain degradation products of AMY2 to lengths exemplified for spots 10 and 28a (spot numbers followed by 'a' refer to a single AMY2 isozyme in a double-spot) as determined by mass spectrometric peptide mapping and applying a minimum chain length (MCL) principle. (Modified from Bak-Jensen et al., 2007).

Figure 2. Subsite mapping of barley $\alpha$-amylases. A. Close-up of the substrate analogue interactions at subsite -7 through +2 as constructed from the crystal structures of AMY1/acarbose and the inactive D180A AMY1/maltoheptaose (Robert et al., 2005). B. Subsite map of AMY1 and AMY2 wild-type as well as T212Y AMY1. C. Subsite map of AMY1 wild-type as well as Y105A/F/W. D. Subsite map of Y105, T212Y and Y105A/T212Y AMY1. The large open arrows illustrate that structural changes in a mutant in one area has effect on the affinity at a remote part of the binding site. The black arrow indicates the catalytic site (Modified from Kandra et al., 2006).

Figure 3. Crystal structure of D180A AMY1 in complex with maltoheptaose (Robert et al., 2005). The granular starch surface binding site is depicted to the left with $\operatorname{Trp}^{278}$ and $\operatorname{Trp}^{279}$ shown in red, while the recently discovered "sugar tongs" is in the lower right corner with $\mathrm{Tyr}^{380}$ in red making contact with maltoheptaose. A maltoheptaose molecule occupies subsites -1 through -7 of the active site cleft. 
Figure $1 \mathrm{~A}$

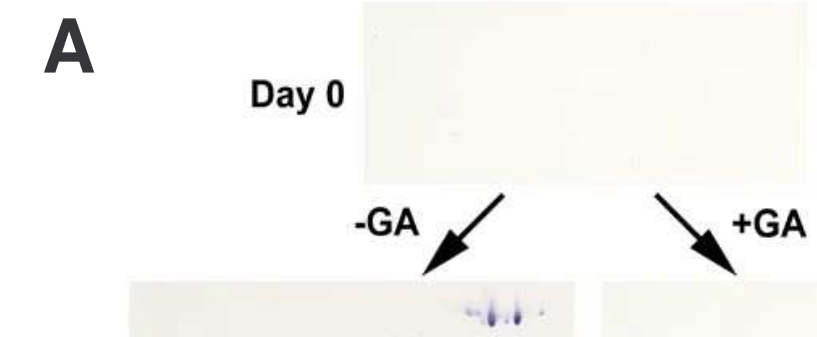

Day 3

Day 4

Day 5

Day 6 
Figure 1 B B
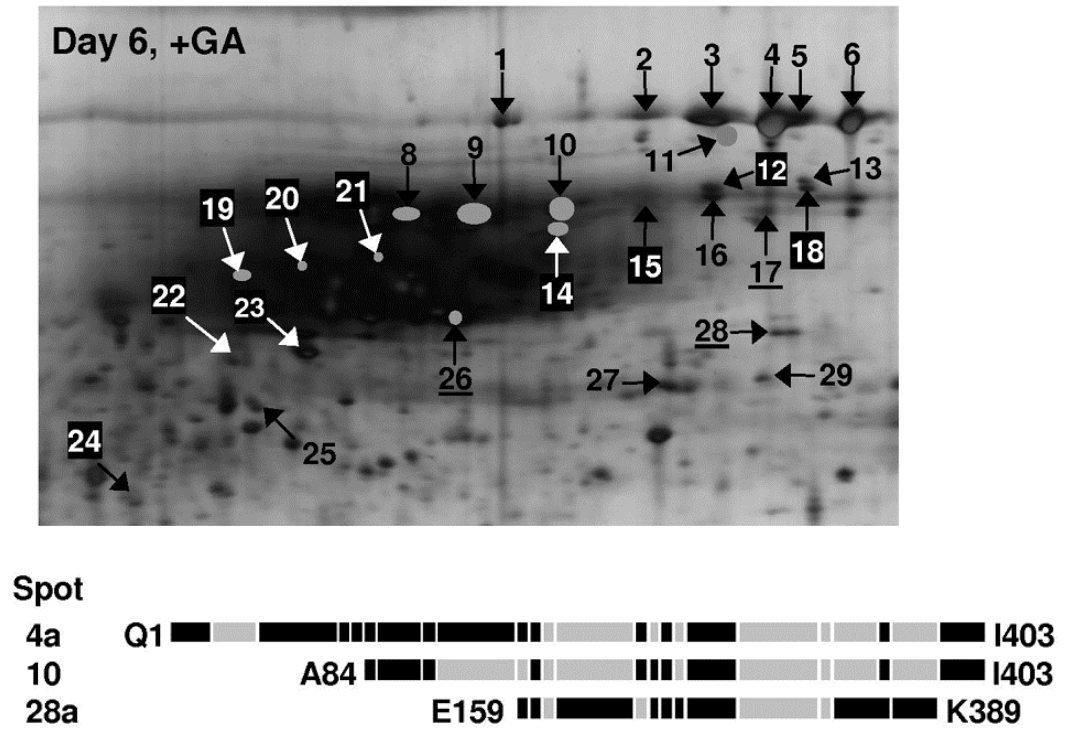

\begin{tabular}{c|c|c|c|c} 
Spot & $\begin{array}{c}\text { Mr (kDa) } \\
\text { (Observed) }\end{array}$ & $\begin{array}{c}\text { Mr (kDa) } \\
\text { (Calculated, MCL) }\end{array}$ & $\begin{array}{c}\text { pl } \\
\text { (Observed) }\end{array}$ & $\begin{array}{c}\text { pl } \\
\text { (Calculated, MCL) }\end{array}$ \\
\hline $4 a$ & 44.84 & 44.930 & 5.87 & 5.62 \\
10 & 38.78 & 35.784 & 5.51 & 5.26 \\
$28 a$ & 32.17 & 25.917 & 5.90 & 5.35
\end{tabular}


Figure 2
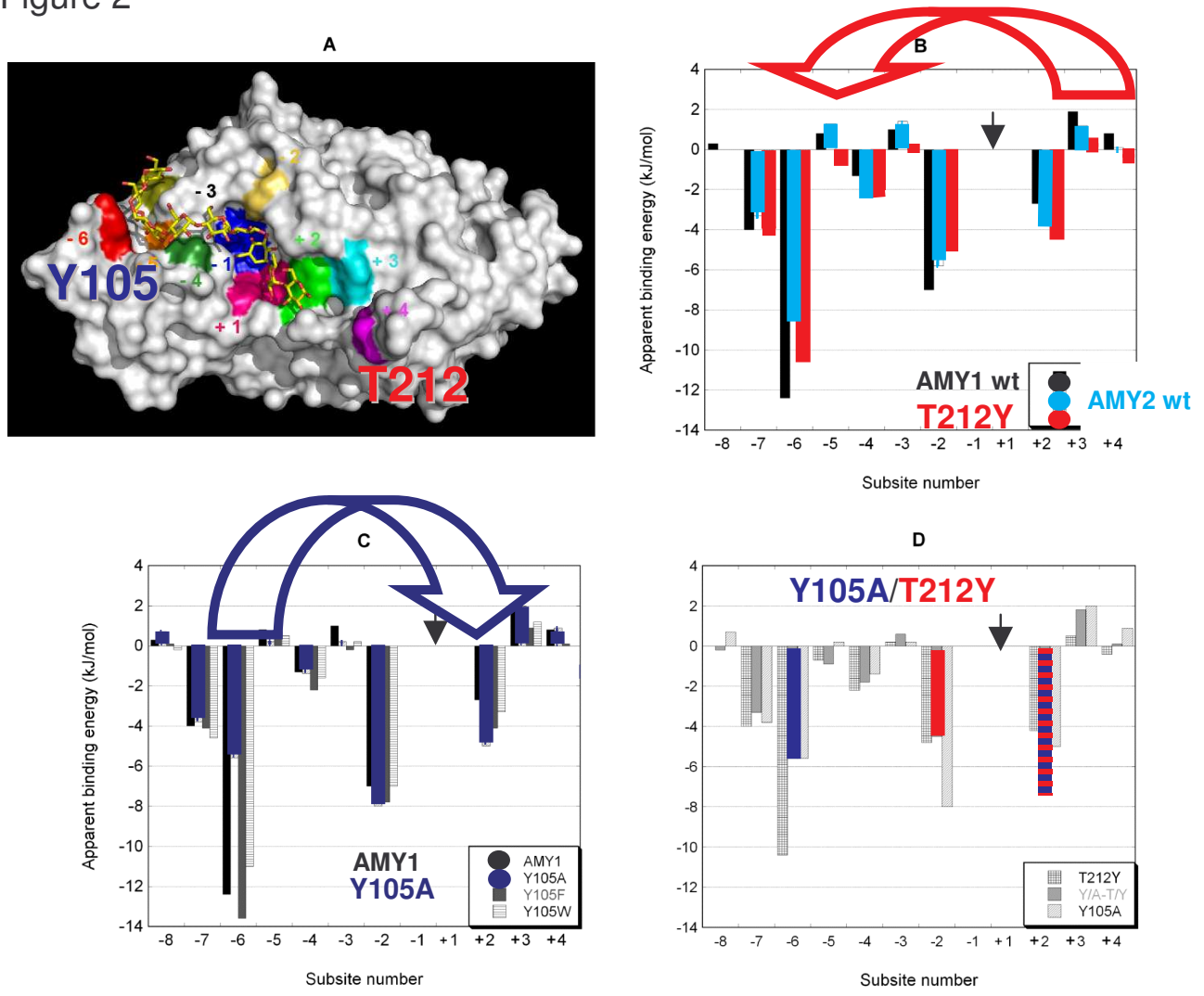
Figure 3

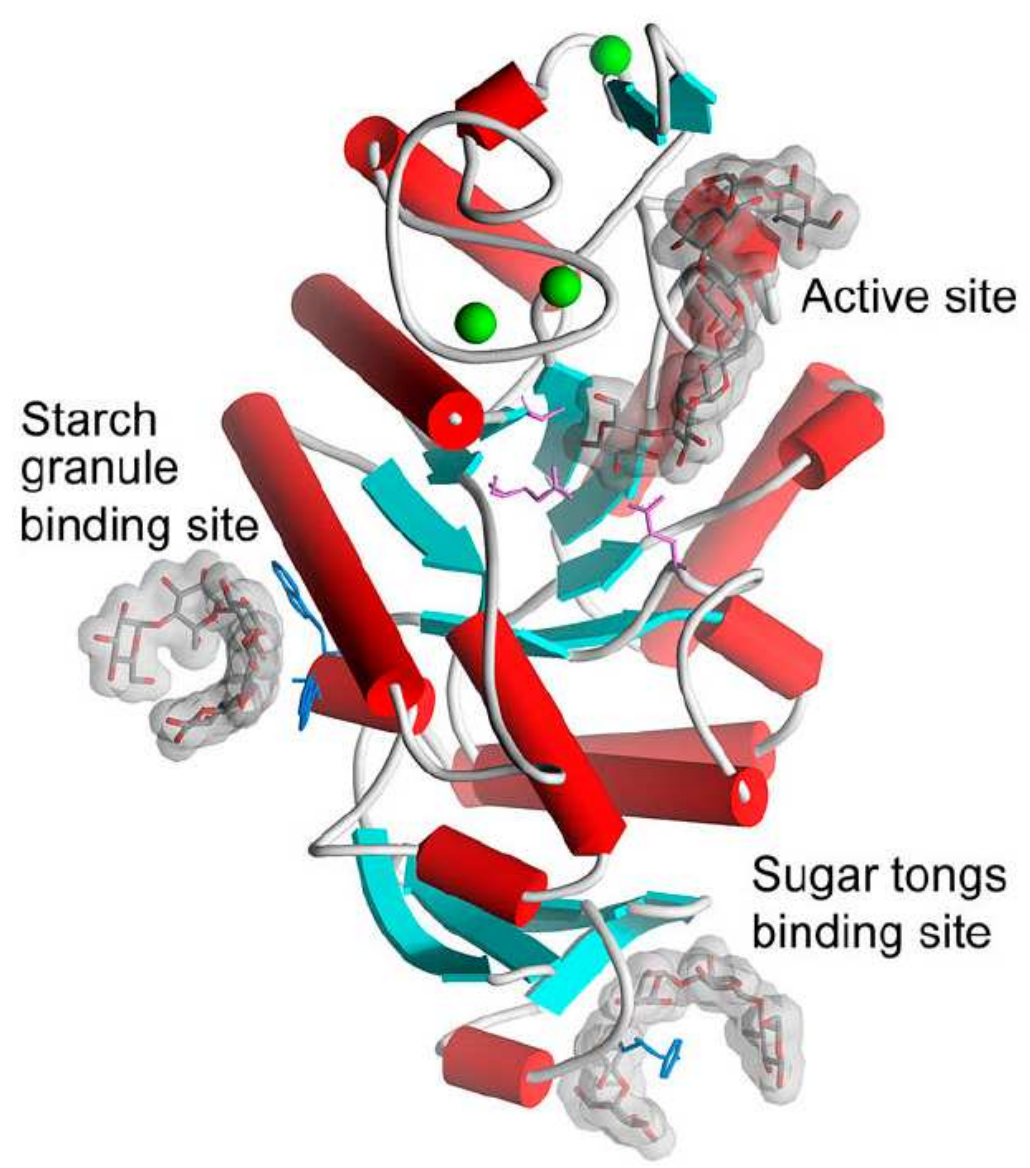

